\title{
"Debo tener esquizofrenia tal vez": experiencia subjetiva y construcción autobiográfica en un adolescente con primer episodio de esquizofrenia
}

\section{"I must have schizophrenia maybe": Subjective experience and autobiographical construction in an adolescent with first episode schizophrenia}

\author{
Marianella Abarzúa \\ Universidad de Chile, Santiago, Chile Pontificia Universidad Católica de Chile, Santiago, Chile
}

\section{Resumen}

En Chile, desde el año 2000, los trastornos psiquiátricos severos han sido una de las siete prioridades programáticas de las políticas públicas de salud mental. El énfasis fue reforzado en 2005, incluyendo el tratamiento del primer episodio de esquizofrenia en el Régimen de Garantías Explícitas en Salud. Este problema de salud mental, de alta relevancia epidemiológica y clínica, acontece habitualmente durante la adolescencia: tiempo de activos procesos de construcción de identidad e historia subjetiva, a los que se suma la experiencia del primer episodio psicótico y su recuperación. El primer episodio de esquizofrenia, ampliamente investigado por la psicología clínica y las ciencias sociales, ha sido insuficientemente abordado desde la perspectiva de las experiencias subjetivas de pacientes en procesos de tratamiento. El objetivo de este estudio fue analizar las experiencias subjetivas asociadas al diagnóstico y tratamiento de un primer episodio de esquizofrenia, a fin de interpretar sus modos de participación en la construcción de un relato autobiográfico. Se trató de un estudio cualitativo interpretativo de caso único, cuyo participante fue un adolescente de 17 años, egresado de un hospital de día para adolescentes de la Región Metropolitana. Fue entrevistado en profundidad y el corpus resultante fue estudiado desde el análisis de discurso, incorporando aportes de la hermenéutica de Ricœur.

\begin{abstract}
In Chile, since 2000, severe psychiatric disorders have been one of the seven programmatic priorities of public mental health policies. This priority was emphasized in 2005, including the treatment of First Episode Schizophrenia in the Regime of Explicit Health Guarantees. This mental health problem, highly relevant in epidemiological and clinical terms, usually occurs during adolescence: a period of active processes of identity construction and subjective history and, added to this, the experience of a first psychotic episode and subsequent recovery. First episode schizophrenia, widely researched in the field of clinical psychology and social sciences, has been insufficiently addressed from the perspective of subjective experiences of patients in treatment. The aim of the study was to analyze the subjective experiences associated with the diagnosis and treatment of first episode schizophrenia, in order to interpret the way these experiences participated in the construction of an autobiographical narrative. This was an interpretive qualitative single case study of a 17 -year-old male participant, discharged from a day hospital for adolescents in the Metropolitan region. He was interviewed in-depth and the resulting corpus was studied based on discourse analysis, incorporating the input from the hermeneutics of Ricœur.
\end{abstract}


Los resultados del estudio sugieren que el adolescente que vive un primer episodio psicótico se enfrenta a complejas experiencias subjetivas sobre su diagnóstico y tratamiento, que se elaboran discursivamente en el contexto de los procesos de reconstrucción autobiográfica.

Palabras clave: esquizofrenia, adolescencia, recuperación, autobiografía, subjetividad.
The results suggest that the adolescent who experienced his first psychotic episode faces complex subjective experiences about diagnosis and treatment, which are discursively elaborated within the context of autobiographical reconstruction processes.

Keywords: schizophrenia, adolescence, recovery, autobiography, subjectivity.

La preparación de este artículo fue financiada en parte por la Comisión Nacional de Investigación Científica y Tecnológica de Chile, Beca de Doctorado Nacional Folio 21120766.

Contacto: M. Abarzúa. Departamento de Psicología, Universidad de Chile. Av. Ignacio Carrera Pinto 1045, Nuñoa, Santiago, Chile. mabarzuac@u.uchile.cl

Cómo citar este artículo:

Abarzúa, M. (2013). "Debo tener esquizofrenia tal vez": experiencia subjetiva y construcción autobiográfica en un adolescente con primer episodio de esquizofrenia. Revista de Psicología, 22(2), 75-86. doi: 10.5354/0719-0581.2013.30855 


\section{Introducción}

Primer episodio de esquizofrenia y políticas públicas de salud mental en Chile

La esquizofrenia, a nivel mundial, exhibe una prevalencia de vida que oscila entre un $0.3 \%$ y un $2.0 \%$, con una media aproximada de $0.7 \%$ y un riesgo relativo hombre-mujer de $1.4 \%$. La tasa de incidencia es de aproximadamente 15.2 por 100000 habitantes al año. En Chile, su prevalencia es de 1.4 a 4.6 personas por cada mil habitantes y su incidencia anual de 12 casos por cada 100.000 habitantes (Ministerio de Salud, 2009). Asimismo, cabe señalar que la esquizofrenia es uno de los problemas de salud mental que más contribuye a la carga global de enfermedades, aportando un $1.9 \%$ del total de años de vida perdidos por muerte prematura y discapacidad en Chile (Ministerio de Salud, 2009). Dichos datos refuerzan la relevancia e interés de desarrollar políticas públicas y programas de salud mental específicamente destinados a esta población, focalizados en sus particularidades, necesidades y características, consenso ampliamente aceptado a nivel mundial (Gleeson, Larsen y McGorry, 2003; McGorry, Killackey y Yung, 2007; Weiden, Buckley y Grody, 2007). En nuestro país, los trastornos psiquiátricos severos han constituido una de las prioridades programáticas declaradas en las políticas de salud mental. Este énfasis ha sido plasmado, por ejemplo, en el "Plan de Salud Mental y Psiquiatría Comunitaria" (Ministerio de Salud, 2000), documento regulador de las políticas públicas del área durante el decenio 2000-2010. Durante el 2005, en el contexto de la última gran reforma de salud, el Estado de Chile reforzó dicho énfasis y estableció la incorporación del primer episodio de esquizofrenia como el primer problema de salud mental con tratamiento garantizado por la Ley 19966, del Régimen General de Garantías Explícitas en Salud.

Tal como ha sido ampliamente reseñado en la literatura psicopatológica, el primer episodio psicótico acontece típicamente durante la adolescencia o el inicio de la vida adulta. Su tratamiento se dirige a sujetos que, mientras luchan por su recuperación, están intentando asumir una condición concebida por la psiquiatría tradicional como potencialmente crónica y discapacitante.

Sin embargo, el campo de la investigación clínica ha instalado un nuevo escenario respecto del primer episodio de esquizofrenia. Por una parte, la hipótesis del "período crítico" (Birchwood, Todd y Jackson, 1998) ha indicado que el tratamiento durante los 2 a 5 años posteriores al primer episodio psicótico resulta determinante en su pronóstico, es decir, un menor tiempo de psicosis no tratada durante el primer episodio se asocia con un mejor pronóstico (Alvarado, 2005;
Baldor, Jerez, Rullas y González, 2008; Ministerio de Salud, 2009; Vallina, Lemos y Fernández, 2006). Por otra parte, los resultados de los estudios longitudinales de seguimiento de los años ochenta y noventa, así como los movimientos de usuarios y familiares de personas con esquizofrenia, han colaborado a la construcción de perspectivas más esperanzadoras sobre su evolución y pronóstico (Myers, 2010). Este nuevo escenario clínico ha favorecido también una ampliación del concepto de recuperación de un episodio psicótico: desde un énfasis centrado en criterios clínicos (disminución de los síntomas) y sociales (desarrollo de relaciones y roles sociales significativos), conceptualizaciones como la de May (2005, citado en Palma, 2007) consideran que existiría una recuperación psicológica, vinculada específicamente con la comprensión y el proceso de dar sentido a la experiencia psicótica.

En tal sentido, el tratamiento del primer episodio de esquizofrenia constituye un escenario pleno de incidencias en los énfasis y focos de la intervención clínica, aspecto aún insuficientemente investigado a nivel internacional y nacional (Weiden, Buckley y Grody, 2007).

Estudios previos han explorado la experiencia subjetiva de pacientes diagnosticados con esquizofrenia y sus transformaciones a lo largo del curso de la enfermedad (Corin, 1998), o el papel de la conciencia de enfermedad como un componente de las identidades que los individuos establecen con posterioridad al diagnóstico de esquizofrenia (Williams, 2008). Sin ir más lejos, propuestas terapéuticas actuales dirigidas a la recuperación del primer episodio de esquizofrenia, han puesto el foco de la intervención terapéutica en el concepto de sí mismo y de identidad personal, con el objetivo de evitar el fenómeno de "inmersión en la enfermedad" (illness engulfment, traducido por autora), donde la identidad personal se pierde y es reemplazada por un sentido de sí definido exclusivamente por la enfermedad (McCay et al., 2006).

Aun así, y especialmente al revisar la investigación desarrollada en países hispanoparlantes, coincidimos con Saavedra (2009) en constatar la escasa atención dada por las ciencias sociales y la psicología a los relatos de pacientes en procesos de tratamiento y rehabilitación. Estos antecedentes subrayan el estudio de las experiencias subjetivas y relatos de personas con esquizofrenia como un fértil ámbito de investigación clínica.

Volviendo al contexto nacional, el programa de tratamiento del primer episodio de esquizofrenia implica ciertas prácticas y procedimientos específicos: toda persona que presente sintomatología sugerente de esquizofrenia ingresará a un programa de intervenciones diagnósticas protocolizadas. En caso de confirmarse el diagnóstico, iniciará un tratamiento que contempla intervenciones farmacológicas y psicosocia- 
les, cuyos lineamientos y énfasis generales están establecidos en la "Guía Clínica de Primer Episodio de Esquizofrenia", actualmente en su segunda versión (Ministerio de Salud, 2009). En lo sustancial, dicha guía refuerza la importancia del tratamiento ambulatorio en dispositivos terapéuticos insertos en la comunidad, evitando la hospitalización completa mientras sea posible. Se buscará el consenso con el usuario y la familia para las decisiones relativas al plan terapéutico, estimulando la participación activa del primero en su recuperación (Ministerio de Salud, 2009).

Si bien ha transcurrido menos de una década desde la promulgación de la ley que garantiza el tratamiento del primer episodio de esquizofrenia, resulta posible afirmar que el recorrido de su implementación (experiencia por cierto siempre local) ha avanzado un trecho suficiente como para formular algunas interrogantes. En particular, la investigación dirigida a rescatar las experiencias subjetivas y relatos asociados a los procedimientos diagnósticos y terapéuticos del primer episodio psicótico, brinda una posibilidad de reconstruir sus efectos a nivel subjetivo y, en consecuencia, de favorecer una retroalimentación sobre las prácticas diagnósticas y terapéuticas. Es pertinente subrayar que dichas prácticas tienen lugar con adolescentes y jóvenes que, por su propia condición etaria y social, se encuentran viviendo activos procesos psíquicos relativos a la construcción de su propia identidad, trabajo al que se suma la experiencia de la enfermedad mental.

El objetivo del estudio fue analizar las experiencias subjetivas asociadas al diagnóstico y tratamiento de un primer episodio de esquizofrenia. Específicamente, interpretar los modos en que dichas experiencias subjetivas participan de la construcción de un relato autobiográfico.

Se trató de un estudio cualitativo de caso único. El caso estudiado correspondió a un adolescente de 17 años, egresado de un hospital de día para adolescentes de la Región Metropolitana. Metodológicamente, el estudio se enmarca en una perspectiva interpretativa orientada desde el análisis de discurso, incorporando aportes de la hermenéutica de Ricœur. La relevancia del estudio se dirige en dos direcciones principales: primero, nuestro país se encuentra desarrollando una política pública de salud mental que recoge la evidencia internacional respecto al carácter crítico de la intervención temprana en el primer episodio de esquizofrenia. En ese sentido, el Régimen de Garantías Explícitas en Salud ha establecido un contexto que instala a un sujeto inédito como destinatario de la práctica diagnóstica y terapéutica: el adolescente que experimenta, por primera vez, las dificultades psicopatológicas y sociales asociadas a una psicosis. Él, al mismo tiempo que soporta esta realidad clínica, se encuentra en el laborioso proceso de construir, de manera mínimamente estable, para sí mismo y para otros, un discurso que dé cuenta de quién es; discurso que solo podrá sostenerse a condición de incorporar también quién ha sido y quién, potencialmente, será en el futuro. Por tanto, estudiar las experiencias subjetivas asociadas al diagnóstico y tratamiento del primer episodio de esquizofrenia y su participación en el proceso de construcción autobiográfica en la adolescencia aborda un problema relevante por su novedad, comprendiendo alcances conceptuales (respecto del sujeto adolescente) y sociales (acerca de las políticas públicas de salud mental).

En segundo lugar, el estudio buscó también dar voz a un sujeto históricamente silenciado y excluido en su participación social: el sujeto con esquizofrenia. La tradición psiquiátrica clásica ha enfatizado como fenómenos centrales de las psicosis el empobrecimiento del lenguaje y la comunicación (Insúa, 1974; Sullivan, 1968). Posteriormente, estudios sobre el discurso en la esquizofrenia (Chaika y Lambe, 1985, 1986) han subrayado que este presentaría desviaciones en diversos niveles lingüísticos, incluyendo la pragmática, aspecto que complejizaría su interpretación. Ahora bien, Chaika y Lambe (1986) también indican que muchas personas con esquizofrenia no presentan, necesariamente, tales alteraciones del discurso. En tal sentido, podemos compartir la apreciación de Díaz (2010) respecto al peso de una tradición psiquiátrica basada en la lingüística formalista, que ha redundado en la exclusión social de un hablante tradicionalmente desposeído de voz, cuya reintroducción al espacio del discurso resulta social y políticamente relevante.

\section{Marco Teórico}

El marco teórico del estudio revisó aportes psicoanalíticos sobre la concepción de adolescencia y los procesos de construcción autobiográfica, propios de este tiempo subjetivo. Asimismo, se recabaron aportes psicoanalíticos sobre aspectos fundamentales de la experiencia psicótica, específicamente los referidos al modo en que el sujeto con psicosis articula las dimensiones temporales del presente-pasado-futuro en la construcción y reconstrucción de su propia autobiografía.

\section{Adolescencia, construcción autobiográfica y temporalidad}

El psicoanálisis, clásicamente, ha abordado el estudio de la adolescencia enfatizando el concepto de identidad: el logro fundamental de este tiempo subjetivo sería el establecimiento de una nueva identidad, luego del abandono de la identidad infantil. Sería este proceso el que motiva que el adolescente atraviese por desequilibrios e inestabilidad extremos, situaciones absolutamente necesarias para él, ya que a través de ellas establecerá su identidad. Para Aberastury y Knobel 
(1970/1995), exponentes paradigmáticos de esta perspectiva clásica: "Ese largo proceso de búsqueda de identidad ocupa gran parte de su energía y es la consecuencia de la pérdida de la identidad infantil que se produce cuando comienzan los cambios corporales" (p. 17). El aspecto clave de la identidad consistiría "en la capacidad del yo de mantener la mismidad y la continuidad frente a un destino cambiante, y por ello la identidad no significa (...) un sistema interno, cerrado, impenetrable al cambio, sino más bien un proceso psicosocial" (Aberastury y Knobel, 1970/1995, p. 50).

Si bien hemos situado preliminarmente la centralidad del concepto de identidad y su construcción durante la adolescencia, resulta necesario desprender algunas derivaciones específicas de este trabajo, en relación al problema de la construcción de la historia subjetiva. Aberastury y Knobel (1970/1995) señalan que los procesos de reestructuración, vividos como una intrusión en el equilibrio alcanzado durante la infancia, "obligan al adolescente, en el proceso para lograr su identidad, a tratar de refugiarse férreamente en su pasado mientras trata también de proyectarse intensamente en el futuro" (p. 55). Los desafíos de la construcción identitaria pueden ser, entonces, releídos enfatizando su dimensión temporal e histórica o, dicho de otro modo, entendidos como el trabajo de construcción de una historia autobiográfica. Esta relectura hace necesaria una referencia a autores que han abordado esta articulación.

Para Aulagnier (1989/1991), la tarea autobiográfica del sujeto jamás termina, constituyendo un trabajo de construcción y reconstrucción permanente del presente. La autora señala que dicho trabajo requiere sostenerse "sobre un número mínimo de anclajes estables de los cuales nuestra memoria nos garantice la permanencia y la fiabilidad" (p. 442). Esta condición es necesaria para que el sujeto logre la certeza sobre la autoría de su propia historia y que los cambios que ella experimentará "no pondrán en peligro esa parte permanente, singular, que deberá transmitirse de capítulo en capítulo, para hacer coherente y que tenga sentido el relato que se escribe" (p. 442).

El trabajo de (re)construcción autobiográfica en la adolescencia comprenderá tal importancia para Aulagnier, que la autora propone incluso una suerte de redefinición del concepto de adolescencia, enfatizando que lo crucial de este tiempo vital será el movimiento temporal continuo, que confronta al aparato psíquico a una serie de esfuerzos de elaboración retrospectiva de esta auto-alteración permanente, manteniendo una ligazón entre el presente y el pasado, que dará sentido a la prueba que el presente impone (1989/1991).
Del mismo modo, como condición y como meta, la (re)construcción autobiográfica debe asegurar al adolescente un saber sobre el futuro, posibilitando nuevas negociaciones que modificarán su relación con la realidad y con los deseos e ideales propios y de los otros (Hornstein et al., 1991).

El trabajo de construcción y consolidación autobiográfica que tendrá lugar en la adolescencia podrá, por cierto, tropezar con escollos. El más severo será la incapacidad de:

lograr tornarse pensable para sí mismo ni tornar pensable y catectizable su propio devenir, hallarse incapacitado de catectizar lo que el flujo temporal le impone como diferencia entre él mismo tal como se piensa, él mismo tal como devendrá y él mismo tal como se descubre deviniendo (Aulagnier, 1979/2007, p. 28).

\section{Construcción autobiográfica y temporalidad en la psicosis adolescente}

La economía psíquica desequilibrada y aún en proceso de construcción, propia de la adolescencia, junto con los nuevos requerimientos relacionales y sociales, sentarán las condiciones de posibilidad de la eclosión de la potencialidad psicótica. Esta ruptura implica la desligazón y el cuestionamiento de las bases mismas de la certeza autobiográfica, diluyéndose el pasado como tal y deteniéndose el propio proceso de historización (Aryan y Torres de Aryan, 2007).

Aulagnier (1979/2007) subrayará las implicancias del compromiso de la capacidad de historización en la psicosis, donde se observará una reducción del campo de posibilidades subjetivas y relacionales, y el futuro aparecerá representado solo como la espera del retorno sin cambios de lo anterior. Por tanto, la experiencia psicótica testimoniará el fracaso del trabajo de puesta en historia, apreciable, por ejemplo, en la confusión temporal del discurso, habitual en la psicosis: "El psicótico está enfrentado a la imposibilidad de constituir y de catectizar ideales, porque no puede catectizar ninguna potencialidad en su yo actual que le asegure un futuro posible" (pp. 41-42, cursivas de la autora). En la psicosis se tratará, entonces, de un peligro real de pérdida de la mismidad y la permanencia, principios fundamentales para dar al sujeto una continuidad autobiográfica suficiente.

Según los aportes revisados, el desafío de la continuidad temporal presente-pasado-futuro, inherente al proceso de construcción autobiográfica adolescente, parece verse redoblado cuando nos situamos en el terreno de la psicosis y sus particularidades psicopatológicas. 


\section{Método}

Como fue señalado, el estudio realizó un análisis de las experiencias subjetivas asociadas al diagnóstico y tratamiento de un primer episodio de esquizofrenia, enfatizando la interpretación de los modos en que estas experiencias subjetivas participan en la construcción de un relato autobiográfico. Se trató de un estudio cualitativo interpretativo de caso único, orientado metodológicamente desde el análisis de discurso, incorporando aportes de la hermenéutica de Ricœur.

Ha sido objeto de amplia discusión la propia definición, tradiciones y prácticas del análisis del discurso, entendido en su versión más amplia como una verdadera perspectiva en ciencias sociales, y en su acepción más acotada como un método de análisis de la lengua en uso (Íñiguez, 2003). Para los fines del estudio, utilizamos una de las definiciones de análisis de discurso sistematizadas por Larraín y Medina (2007): "conjunto de aproximaciones al estudio del lenguaje que comparten el hecho de entenderlo como lengua viva, corporeizada, perteneciente a un contexto específico y a hablantes particulares" (p. 4). En ese sentido, análisis de discurso comprendido como una herramienta de análisis de las producciones discursivas, que posibilita la aprehensión (y la re-introducción) de "la subjetividad presente en todo discurso" (Larraín y Medina, 2007, p. 6). Se trata, a nuestro juicio, de un enfoque metodológico pertinente a la pregunta de investigación, en tanto los procesos de construcción autobiográfica se despliegan, actualizan y -valga la redundanciaconstruyen en el campo de la subjetividad discursiva.

Así como la definición del análisis de discurso reviste complejidades inherentes a la multiplicidad de sus tradiciones y prácticas, la noción de discurso está sujeta a la misma condición de diversidad y pluralidad. Dado que la revisión (incluso sintetizada) de la polisémica noción de discurso excede los alcances y propósitos del estudio, nos limitaremos a enunciar, con Íñiguez (2003), la definición de discurso que sostuvo el ejercicio analítico desarrollado: "conjuntos de enunciados dichos en un contexto de interacción -en esta concepción se resalta el poder de acción del discurso sobre otra u otras personas, el tipo contexto (sujeto que habla, momento y espacio, historia, etc.)" (p. 97).

Otras referencias que permitieron nutrir esta definición -y, al mismo tiempo, las prácticas de análisis sostenidas- fueron algunas nociones sobre la hermenéutica y el discurso, desarrolladas por Ricœur (1971/2001a, 1975/2001b). Revisaremos brevemente estas referencias, en su función de orientaciones para la aplicación de nuestro método de análisis.
Ricœur centra el problema de la hermenéutica en la noción de discurso, intentando caracterizar el discurso como una realización del lenguaje, como una obra estructurada. Para comprender la noción del discurso como realización, revisará el carácter de acontecimiento inherente al discurso. En sus propias palabras, "algo sucede cuando alguien habla" (Ricœur, 1975/2001b, p. 97), el discurso se realiza siempre en el tiempo y en el presente, remite indefectiblemente al hablante y tiene, por tanto, un carácter autorreferencial: "alguien habla, alguien se expresa al tomar la palabra” (Ricœur, $1975 / 2001$ b, p. 98). Lo que podríamos traducir, en términos metodológicos, por la pregunta: ¿quién habla en el discurso? Del mismo modo, el discurso implica también un otro, un interlocutor a quien está dirigido. Se trata entonces de un acontecimiento que tiene lugar en el intercambio. En clave metodológica: ¿a quién es el otro al que se dirige el discurso?

Sobre la dimensión del discurso en tanto obra, Ricœur la vincula con la referencia al significado o sentido, que brinda perdurabilidad al discurso (más allá de la fugacidad del acontecimiento): habría una centralidad del decir en lo dicho, una centralidad de la pregunta “¿qué es lo que se dice?” (Ricœur, 1975/2001b, p. 99).

Para el autor, la noción del discurso como obra brindaría una "mediación práctica entre la irracionalidad del acontecimiento y la racionalidad del sentido" (Ricœur, 1975/2001b, p. 102). En tanto práctica, la actividad discursiva es "considerada junto con su contexto complejo y en particular las condiciones sociales que le dan significado en un mundo efectivamente vivido" (Ricour, 1975/2001b, p. 101). Se subrayan entonces la dimensión social de la práctica discursiva y su temporalidad, el tiempo social, la dimensión del acontecimiento que imprime su marca sobre la época. En términos metodológicos: ¿cuál es el contexto?, ¿cuál es la temporalidad involucrada?

La comprensión del discurso como obra implica cambios en la noción de sujeto de discurso, que Ricœur vinculará a la noción de autor (1975/2001b). De todos modos, y en tensión con la dimensión social de la acción discursiva, la atribución de responsabilidad o de autoría respecto de acciones complejas resultará, para Ricœur, un ejercicio problemático.

Por tanto, la pregunta ¿quién habla? parece abrirse a más de un sujeto discursivo. La complejidad de establecer la autoría discursiva podría enfatizarse en el discurso de una persona con esquizofrenia, si consideramos la etimología de esta palabra ("mente fragmentada") y el modo en cómo ha marcado la práctica psicopatológica y clínica construida en torno a ella. 
La noción de discurso como obra permite, asimismo, situar de otro modo lo que Ricœur entenderá como el mundo del texto, esto es, la referencia o denotación del discurso:

En efecto, lo dado a interpretar en un texto es una proposición de mundo, de un mundo habitable para proyectar allí uno de mis posibles más propios. Es lo que llamo el mundo del texto, el mundo propio de este texto único (Ricœur, 1975/2001b, p. 107, cursivas del autor).

Esta proposición de mundo, más que tratarse de una entidad ya dada y/o impuesta, es ante todo un "poder-ser" (Ricœur, 1975/2001b, p. 108, cursivas del autor).

Dejaremos en este punto las referencias que ampliaron la definición de discurso que orientó nuestro trabajo de análisis, para dar cuenta de los aspectos metodológicos relativos a la muestra, técnica de producción de datos y procedimiento de análisis.

El estudio actual deriva desde un corpus ya establecido y consiste en una entrevista biográfica en profundidad. Esta entrevista fue seleccionada entre un grupo de seis entrevistas realizadas en el marco de una investigación previa (Abarzúa, 2010), que exploró los significados asociados al diagnóstico y tratamiento del primer episodio de esquizofrenia y sus consecuencias en los procesos de conformación identitaria de adolescentes y jóvenes usuarios de un hospital de día para adolescentes.

La muestra del estudio original estuvo conformada por seis adolescentes y jóvenes entre 15 y 21 años (cuatro hombres y dos mujeres), diagnosticados con un primer episodio de esquizofrenia, en tratamiento en un hospital de día para adolescentes de la Región Metropolitana. Todos los participantes se encontraban en fase de recuperación y/o reintegración social, criterio relevante por razones clínicas y de ética investigativa. Su participación requirió la entrega de consentimiento o asentimiento informado por escrito, ratificado por el consentimiento informado de las madres en el caso de los participantes menores de edad. Las entrevistas fueron registradas por medio de grabaciones de audio, a objeto de facilitar la transcripción y análisis del material producido.

Los datos muestrales del participante cuya entrevista será analizada en el presente estudio son los siguientes: adolescente de sexo masculino, 17 años, estudiante (en modalidad de exámenes libres), con una hospitalización psiquiátrica previa a su tratamiento en el hospital de día, centro donde estuvo en tratamiento 1 año y 6 meses. Al momento de la entrevista se encontraba egresado del hospital de día hacía cinco meses, manteniendo su tratamiento ambulatorio en un centro de salud pública. El criterio utilizado para respaldar su estabilización psicopatológica fue la evaluación clínica del equipo tratante, sin utilizar un instrumento complementario (e.g., Escala de Síndromes Positivo y Negativo para Esquizofrenia, PANSS). Esta decisión metodológica, que puede ser considerada una debilidad del estudio, se fundamentó en que el hospital de día no aplicaba estos instrumentos de evaluación clínica en forma sistemática y, por tanto, no contaba con ese dato. Al respecto cabe señalar que, de acuerdo al estudio de Markkula, Alvarado y Minoletti (2011), solo un $26 \%$ de los pacientes tratados por un primer episodio de esquizofrenia contaba con escalas de evaluación psicopatológica en sus fichas clínicas; se trataría, entonces, de una circunstancia clínica habitual. En ese escenario, se priorizó el criterio clínico del equipo tratante, a fin de simplificar la fase de recolección de datos y evitar un potencial riesgo de desestabilización para el participante.

El hospital de día en donde se desarrolló el estudio ofrecía un programa de tratamiento ambulatorio para 14 adolescentes beneficiarios del sistema público de salud, de entre 14 y 19 años al momento de su ingreso, derivados desde otros centros de nivel secundario y terciario de la red de salud mental. Los adolescentes habían participado de procesos de confirmación diagnóstica en sus centros de origen, por tanto el primer episodio de esquizofrenia estaba confirmado al momento de ingresar al hospital de día. Su programa terapéutico estaba a cargo de un equipo multidisciplinario, cuyas orientaciones clínicas se apoyaban en aportes de la psiquiatría comunitaria y el psicoanálisis. El centro concluyó su funcionamiento en diciembre de 2011.

El análisis de discurso realizado tomó una perspectiva interpretativa, intentando situar y responder a las preguntas que se desprenden de la propuesta de Ricœur: ¿quién habla en el discurso?, ¿a quién es el otro al que se dirige el discurso?, ¿qué es lo que se dice?, ¿cuál es el contexto y la temporalidad involucrados? y ¿cuál es el mundo, el "poder-ser" que propone el discurso?

Respecto de la pregunta ¿quién habla en el discurso?, consideramos que se engarza con la propuesta de definición de sujeto discursivo que establece la tradición del Análisis Dialógico del Discurso (Larraín y Medina, 2007), quienes lo conceptualizan como el sujeto que representa al hablante en su conjunto, en su totalidad: "quien imprime en el enunciado su intencionalidad. (...) quien no se marca directamente y de quien solo se construye una imagen a través del recorrido textual" (p. 30). 


\section{Resultados}

Como indicamos previamente, el objetivo que guió el estudio fue describir las elaboraciones discursivas acerca de la propia construcción autobiográfica, y los modos en que la experiencia del diagnóstico y tratamiento del primer episodio de esquizofrenia participan de dicha construcción. Con el fin de responder a este objetivo, el corpus del estudio fue analizado bajo la modalidad de preguntas dirigidas al discurso del participante.

A continuación se presentan los extractos seleccionados en nuestro análisis, incorporando entre corchetes referencias necesarias para tornar más inteligible la narración. Se han utilizado puntos suspensivos (...) para indicar pausas en el relato, o bien que se tomó solo una parte del texto. Excepcionalmente, hemos incluido la transcripción de secuencias de habla participante-investigadora (identificada como "E").

\section{Primer extracto:}

"Sí, me diagnosticaron esquizofrenia. Antes de venir acá estuve en el [Hospital] ${ }^{1}$ y me diagnosticaron esquizofrenia paranoide catatónica, tenía eso y sí estaba informado aquí y de todo lo que sucedía en torno a mí....”

\section{$(\ldots)$}

"No entendía muy bien, pero tenía y me revisaban nomás, eso fue lo que me dijeron, dijeron que 'podría ser esquizofrenia, no dijeron 'es esquizofrenia"'.

Respecto de la pregunta ¿qué se dice?, observamos diversas dimensiones discursivas en juego. Por una parte, enunciados que reconstruyen y dan cuenta de la trayectoria del procedimiento diagnóstico vivido por el sujeto: "antes de venir acá estuve en el [Hospital] y me diagnosticaron esquizofrenia paranoide catatónica". Por otra, enunciados que parecen dar cuenta de un posicionamiento que el hablante toma con respecto a la experiencia del diagnóstico: "sí estaba informado aquí y de todo lo que sucedía en torno a mí (...) No entendía muy bien (...) dijeron que 'podría ser esquizofrenia', no dijeron 'es esquizofrenia'. Parece haber un primer momento donde el sujeto discursivo refiere una participación activa en las informaciones relevantes sobre su propia situación, no resultando evidente si esta participación deriva de una cierta agencialidad ejercida en el proceso -demandando activamente información sobre el diagnóstico- o, más bien, del rol activo de los agentes sanitarios implícitos en el "dijeron".
En un segundo tiempo, aparece mayor confusión sobre el procedimiento diagnóstico en el hablante, quien de todos modos permanece en un registro atento a ciertas sutilezas discursivas en la enunciación del diagnóstico ("dijeron que 'podría ser esquizofrenia', no dijeron 'es esquizofrenia"'), sin que resulte claro aún el sentido de esta precisión para el sujeto discursivo.

Segundo extracto:

“...yo quería ir donde una psicóloga porque eso [muy presionado, mucha ansiedad] no era normal y eso ya lo sentía desde hace tiempo, como desde dos años, pero nunca había sido tan fuerte (...) y la psicóloga me atendió y me dijo que esa ansiedad es estrés y depresión y yo pensé que te daban algún... para ver si tenía esquizofrenia, pero en el fondo... ¿cómo se llama?, o sea como para saber si tenía esquizofrenia...”.

\section{$(\ldots)$}

"No, ya desde chico ya creía que tenía esquizofrenia, no sé por qué tenía unos sueños del futuro, no sé (...) y que iba a tener esquizofrenia y pensaba 'debo tener esquizofrenia tal vez' desde muy chico, como de los 8 ...”.

En este extracto resulta posible apreciar dos elementos principales: por una parte, se despliega una compleja temporalidad discursiva respecto del diagnóstico y su relación con el hablante, cuyos tempos intentaremos ir precisando a continuación. Por otra, aparece un mundo discursivo, un "poderser" o - más bien - un "poder-tener" esquizofrenia, en el que el hablante parece estar representado subjetivamente. Desarrollaremos estas consideraciones a continuación.

El hablante describe una serie de experiencias subjetivas a las que da un carácter altamente displacentero (psicopatológico, podríamos traducir), presentes desde la niñez, que parecen operar como la referencia de su elaboración discursiva sobre sí mismo. Se trataría de aquel elemento vivencial que moviliza una construcción autobiográfica posible, entendida como un proceso que concierne activamente al hablante y cuya temporalidad resulta altamente compleja: "ya desde chico ya creía que tenía esquizofrenia (...) y que iba a tener esquizofrenia y pensaba 'debo tener esquizofrenia tal vez' desde muy chico, como de los ocho..... El sujeto discursivo oscila entre el "tenía", "iba a tener", "debo tener"... ¿oscilación temporal inherente a un relato que revisita retrospectivamente la infancia? ¿Al propio tiempo de la adolescencia?

${ }^{1}$ Institución donde ocurrió su hospitalización psiquiátrica. 
¿A las particularidades psicopatológicas del hablante? ¿A su resistencia ante la posibilidad de una enfermedad mental? ¿A todos estos contextos? No resulta sencillo arriesgar una interpretación.

\section{Tercer extracto:}

"No, antes que me diagnosticaran esquizofrenia yo decía: 'yo estoy loco', y me ponía a llorar, hasta que a los 11 años yo decía: 'estoy loco, qué voy hacer ahora', pero cuando fui más grande y me dijeron que tenía esquizofrenia, lo tomé bien...".

E: "A lo mejor esta es una pregunta difícil de responder (...) porque a los ocho años estar pensando en esquizofrenia, de hecho la esquizofrenia no es una palabra de uso muy común, ¿ por qué crees que estaba en ti esa idea, cómo crees que llegaste a tener esa idea?".

"Es que yo leía hartos libros, desde chico leía libros de psicología, algunas partes, también leí un tiempo, eso fue cuando era más grande, como a los 11 o 12 años, ahí un libro que trajo mi hermano que se llama 'Eneagrama' (...) y yo leí todo el libro y yo me identificaba más con el estado insano y no sé, yo decía, 'sí, para mí que soy esto' y el que está más ligado a la esquizofrenia (...) y por eso es que estaba informado de la esquizofrenia".

En este extracto, el hablante parece reforzar las interpretaciones dadas al fragmento anterior: las experiencias subjetivas de angustia y desesperación movilizan en él una activa búsqueda de palabras que le den sentido, donde la referencia a la esquizofrenia parece aquietar la vivencia de despersonalización: frente a la angustia de "estoy loco, qué voy a hacer ahora", la palabra esquizofrenia parece acotar, poner límite a dicha experiencia de sufrimiento.

Ahora bien, caben preguntas sobre la temporalidad que el sujeto discursivo enuncia: ¿se trata de una investigación y construcción efectivamente iniciada en la infancia, a objeto de preservar un saber sobre sí mismo allí donde el sujeto vive la experiencia de severas angustias? Esta variante interpretativa del material permitiría plantear que para el hablante, en algún punto, el diagnóstico sería más un momento de reconocimiento de un saber sobre sí mismo, que el encuentro con una oferta de sentido autobiográfico radicalmente nueva: "cuando fui más grande y me dijeron que tenía esquizofrenia lo tomé bien..... Una interpretación alternativa sobre el mismo fragmento sería la siguiente: ¿se trata de una (re) construcción discursiva efectuada a posteriori del diagnóstico, como modo de avenirse con una oferta de sentido que sobreviene de manera exterior a su propia experiencia? Retengamos esta alternativa para el análisis del último extracto.

\section{Cuarto extracto:}

“...yo no creía que tenía esquizofrenia y cuando me diagnosticaron yo pensaba que se habían equivocado y la que me confirmó fue la doctora $\mathrm{X}$, porque yo le pregunté: '¿qué tengo, por qué tomo pastillas?' y me dijo: 'es que tú eres esquizofrénico paranoide catatónico' y al principio no sé, sentí que yo no esperaba eso, que como que ya desde chico pensaba que tenía...”.

\section{(...)}

"Sí, yo creo que sí [hubo un quiebre], antes que me diagnosticaran, como a los 12, no sé si era más feliz, no lo sé, pero aunque yo tenía voces en mi cabeza, pero era y tenía también momentos de vacío de repente, era feo, pero creo que esta sensación [el diagnóstico] fue peor que una operación de peritonitis (...)”.

E: “(...) si comparas tu vida de antes del diagnóstico con la de ahora, después del diagnóstico, ¿isientes que cambió en algo tu vida?".

"No, pero como dije antes, cuando yo era más chico, yo era más feliz, aunque sentía estas sensaciones de vacío, tenía como más convicciones sobre el amor, el amor a las personas y algo cambió en eso".

Resulta particularmente interesante la vacilación o resistencia que el hablante manifiesta frente a la experiencia del diagnóstico en este último extracto, en contraste con el fragmento anterior: la palabra que previamente habría sido "bien tomada" deviene inesperada, signada con el carácter de una experiencia altamente displacentera y origen de un cambio: "cuando yo era más chico, yo era más feliz, aunque sentía estas sensaciones de vacío, tenía como más convicciones sobre el amor, el amor a las personas y algo cambió en eso". ¿Cómo podemos entender este cambio en la subjetividad discursiva?

En la pregunta y el diálogo por la construcción de la propia historia autobiográfica, este extracto muestra de manera más palpable un nuevo contexto, un nuevo hablante ("la doctora"). Podemos apreciar, en el modo en que se articula el diálogo entre el adolescente y la médico, un matiz palpable en la pregunta por su padecer: "yo le pregunté: '¿qué tengo, por qué tomo pastillas?' y me dijo: 'es que tú eres esquizofrénico paranoide catatónico"'. De acuerdo a su propia experiencia y reconstrucción discursiva, el adolescente formula su pregunta en términos de "tener" y el discurso médico responde en términos de "ser". Un nuevo mundo o referente del discurso parece abrirse desde acá para el hablante, si consideramos que la pregunta por la propia historia es, finalmente, la pregunta por el ser del sujeto. ¿Es a la esencialización de su propia experiencia psicopatológica a la que el sujeto discursivo se resiste? 
Un último aspecto a destacar es que el extracto parece dar cuenta, en una articulación discursiva muy sutil, de la compleja intrincación entre continuidad y quiebre biográfico: en lo explícito, el hablante afirma su sensación de continuar siendo el mismo (continuidad), pero la experiencia del diagnóstico, significada como "peor que una operación de peritonitis", parece transformar la cualidad de sus experiencias: "yo era más feliz, aunque sentía estas sensaciones de vacío, tenía como más convicciones sobre el amor, el amor a las personas y algo cambió en eso". Ahora bien, ¿ $₫$ se trata efectivamente del origen del conflicto autobiográfico? ¿O sería la manifestación del impasse autobiográfico, que habría sobrevenido inevitablemente para este sujeto?

\section{Discusión y conclusiones}

El marco conceptual del estudio subrayó la centralidad de la construcción de la historia autobiográfica en la adolescencia, como un recurso que brinda posibilidades de permanencia y continuidad psíquicas a un sujeto que vive tiempos de inestabilidad y desequilibrio. El dinamismo de los procesos de construcción y reconstrucción autobiográfica sitúan al adolescente en un complejo trabajo de articulación de las dimensiones temporales pasado-presente-futuro: dejar de ser lo que un día fue para, desde los avatares de su experiencia presente, proyectarse hacia un futuro posible.

Si la construcción de una historia autobiográfica constituye un desafío para todo adolescente, el marco psicopatológico que instala la experiencia de la psicosis parece redoblar las dificultades inherentes a este trabajo de historización. Según los antecedentes teóricos presentados, la psicosis diluiría las bases de la certeza autobiográfica y detendría el proceso de historización. Específicamente, el adolescente con psicosis quedaría situado en el lugar de un historiador desposeído de movilidad interpretativa, sin opción de anticipar e investir un futuro posible.

Junto con estos aportes teóricos, revisamos antecedentes surgidos del campo de la investigación clínica sobre primer episodio de esquizofrenia, que parecen haber instalado un escenario más esperanzador para su tratamiento, evolución y pronóstico. Específicamente, subrayamos la relevancia de los procesos de recuperación psicológica de un episodio psicótico, que estarían vinculados con el proceso de comprender y dar sentido a la experiencia psicótica.

Los resultados del estudio, pese a las limitaciones metodológicas inherentes al análisis de un caso único, permiten presentar una comprensión preliminar de las complejas elaboraciones discursivas desarrolladas por un adolescente que experimenta una psicosis. Lejos de ocupar el lugar de un personaje secundario, pasivo, simple receptor de una experiencia y una prác- tica diagnóstico-terapéutica que no puede comprender o representarse, los extractos permiten acceder a la vivencia de un adolescente que no solo elabora discursivamente experiencias vinculadas a su diagnóstico y tratamiento, sino que también intenta articularlas en una dialéctica temporal autobiográfica presente-pasado. A partir del esfuerzo retrospectivo que intenta dar sentido a la experiencia de la enfermedad del presente, el adolescente rememora y articula sus experiencias de sufrimiento infantil: para él, la posibilidad de la esquizofrenia parecía estar instalada desde mucho antes del diagnóstico médico, en sus propias palabras: "pensaba 'debo tener esquizofrenia tal vez' desde muy chico, como de los 8". Cabe reflexionar sobre el alcance de las intervenciones psicoterapéuticas que el participante desarrolló durante su periodo de tratamiento en el hospital de día y la posible influencia de estas en sus procesos de reconstrucción autobiográfica, interrogante para futuros estudios.

Ahora bien, el corpus analizado indica que la temporalidad de este sujeto discursivo es compleja y conflictual: en este fragmento, ¿el sujeto brinda el testimonio de un fragmento de su infancia, como una fidedigna pieza de verdad histórica? ¿Nos habla de su infancia desfigurada por la rememoración a posteriori, desde el prisma de la enfermedad del presente? Se trata, incluso, de alternativas de interpretación del material que no resultan mutuamente excluyentes, si consideramos que este hablante parece poder relatarse a sí mismo en continuidad más que en quiebre autobiográfico. Este resultado, en la misma línea de los hallazgos de Adame y Hornstein (2006) sobre narrativas de continuidad en experiencias de sufrimiento emocional y locura, sugiere la necesidad de reexaminar las conceptualizaciones sobre la capacidad de historización del sujeto con psicosis, abriendo perspectivas a la posibilidad de dar un sentido autobiográfico a dicha experiencia.

Sin embargo, es preciso considerar que el análisis sugiere, al mismo tiempo, puntos de mayor impasse en la construcción autobiográfica que realiza este hablante. En efecto, sus elaboraciones discursivas no dan cuenta de referencias a un futuro investido como potencialidad. El movimiento parece realizarse desde el presente de la enfermedad al pasado infantil y viceversa, sin avanzar más allá.

Sobre los alcances del diagnóstico en la construcción autobiográfica, resulta pertinente subrayar el fragmento que alude al espacio dialógico con la médico. Señalamos que, en ese punto, el hablante da cuenta de una vacilación o resistencia. Si previamente parecía tratarse de un sujeto discursivo en continuidad biográfica, la respuesta "es que tú eres esquizofrénico paranoide catatónico" parece introducir un elemento inesperado en la construcción autobiográfica, incluso para un sujeto que pensaba en la esquizofrenia desde la niñez: " $y$ 
al principio no sé, sentí que yo no esperaba eso, que como que ya desde chico pensaba que tenía...". En este punto, el mundo del sujeto discursivo hace referencia a una experiencia de sufrimiento y de cambio, que es articulada de manera conflictual: si bien continúa relatándose en continuidad biográfica, la cualidad de sus experiencias parece vivir un quiebre: "yo era más feliz (...) algo cambió en eso".

Resulta problemático, recogiendo las metáforas de Ricœur, establecer con precisión la autoría de este conflicto en la construcción autobiográfica: ¿se trata de la reacción de un sujeto discursivo vulnerable en sus capacidades de historización, frente a la marca discursiva de un hablante de mayor poder? ¿ $\mathrm{O}$ la expresión de una frágil capacidad de representarse en una construcción autobiográfica coherente, testimonio de su propia psicopatología? Considerando las dimensiones subjetivas y sociales en juego, realizar un análisis basado en opciones excluyentes podría implicar el riesgo de reducir artificialmente este fenómeno. A este respecto, futuras investigaciones orientadas según una perspectiva dialógica de análisis podrían dar mayor luz sobre sus complejidades e imbricaciones.

Se requiere, por tanto, proseguir el estudio de adolescentes que experimentan un primer episodio de esquizofrenia, a fin de precisar las particularidades discursivas implicadas en sus procesos de construcción autobiográfica. La riqueza y complejidad dialógica del discurso analizado, aún en sus conflictos e impasses, ¿daría cuenta de la peculiar singularidad de un adolescente extraordinario? $¿ \mathrm{O}$, por el contrario, de un trabajo de construcción y reconstrucción biográfica posible, inherente a la experiencia de la psicosis en la adolescencia y a sus modos de diagnóstico y tratamiento? Son algunas de las preguntas que la investigación posterior podrá continuar desarrollando.

\section{Referencias}

Abarzúa, M. (2010). Diagnóstico de primer episodio de esquizofrenia: trayectorias de adolescentes (Tesis inédita de magíster). Universidad de Chile, Santiago, Chile.

Aberastury, A. y Knobel, M. (1995). La adolescencia normal. Un enfoque psicoanalítico. Buenos Aires: Paidós. (Trabajo original publicado en 1970).

Adame, A. y Hornstein, G. (2006). Representing madness: How are subjective experiences of emotional distress presented in firstperson accounts? The Humanistic Psychologist, 34(2), 135-158. doi: 10.1207/s15473333thp3402_3

Alvarado, R. (2005). Evaluación de una intervención comunitaria para la detección precoz y tratamiento oportuno de personas con primer episodio de psicosis. (Proyectos I+D en Salud SA05I20059). Santiago: Comisión Nacional de Investigación Científica.

Aryan, A. y Torres de Aryan, D. (2007). Notas para la comprensión de la predisposición psicótica en la pubertad y adolescencia. Psicoanálisis, 29(2), 255-276.

Aulagnier, P. (1991). Construir(se) un pasado. Psicoanálisis, 13(3), 441-497. (Trabajo original publicado en 1989).

Aulagnier, P. (2007). Los destinos del placer. Alienación, amor, pasión. Buenos Aires: Paidós. (Trabajo original publicado en 1979).

Baldor, I., Jerez, M., Rullas, M. y González, J. (2008). Sobre la oportunidad de la rehabilitación psicosocial tras un primer brote: un caso clínico. Revista de la Asociación Española de Neuropsiquiatría, 28(2), 433-449. doi:10.4321/S021157352008000200014

Birchwood, M., Todd, P. y Jackson, C. (1998). Early intervention in psychosis. The critical period hypothesis. The British Journal of Psychiatry Supplements, 172(33), 53-59.
Corin, E. (1998). The thickness of being: Intentional worlds, strategies of identity, and experience among schizophrenics. Psychiatry, 61(2), 133-146.

Chaika, E. y Lambe, R. (1985). The locus of dysfunction in schizophrenic speech. Schizophrenia Bulletin, 11(1), 8-15. doi:10.1093/schbul/11.1.8

Chaika, E. y Lambe, R. (1986). Is schizophrenia a semiotic disorder? Replies to Harrod. Schizophrenia Bulletin, 12(1), 1415. doi:10.1093/schbul/12.1.14

Díaz, N. (2010). Una reflexión acerca de la construcción discursiva de la enfermedad en pacientes psicóticos. Texturas, 9-10, 95-111.

Gleeson, J., Larsen, T. y McGorry, P. (2003). Psychological treatment in pre- and early psychosis. The Journal of the American Academy of Psychoanalysis and Dynamic Psychiatry, 31(1), 229-245. doi:10.1521/jaap.31.1.229.21933

Hornstein, L., Aulagnier, P., Pelento, M., Green, A., Rother, M., Bianchi, H.,...Bosoer, E. (1991). Cuerpo, historia, interpretación. Piera Aulagnier: de lo originario al proyecto identificatorio. Buenos Aires: Paidós.

Insúa, J. (1974). Psicosemiología y psicopatología: introducción a la psicoterapia en la práctica médica. Texas: Columba.

Íñiguez, L. (2003). El análisis del discurso en las ciencias sociales: verdades, tradiciones y práctica. En L. Íñiguez (Ed.), Análisis del discurso: manual para las ciencias sociales (pp. 83-123). Barcelona: Editorial UOC.

Larraín, A. y Medina, L. (2007). Análisis de la enunciación: distinciones operativas para un análisis dialógico del discurso. Estudios de Psicología, 28, 283-301. doi:10.1174/021093907782506443 
Ley $\mathrm{N}^{\circ}$ 19966. Diario Oficial de la República de Chile, Santiago, Chile, 3 de septiembre de 2004. Recuperado de http://www. leychile.cl/N?i=229834\&f=2004-09-03\&p

Markkula, N., Alvarado, R. y Minoletti, A. (2011). Adherence to guidelines and treatment compliance in the Chilean national program for first-episode schizophrenia. Psychiatric Services, 62(12), 1463-1469. doi:10.1176/appi.ps.001042011

McCay, E., Beanlands, H., Leszcz, M., Goering, P., Seeman, M., Ryan, K.,...Vishnevsky, T. (2006). A group intervention to promote healthy self-concepts and guide recovery in first episode schizophrenia: A pilot study. Psychiatric Rehabilitation Journal, 30(2), 105-111. doi:10.2975/30.2006.105.111

McGorry, P., Killackey, E. y Yung, A. (2007). Early intervention in psychotic disorders: detection and treatment of the first episode and the critical early stages. Medical Journal of Australia, 187(7), S8-S10.

Ministerio de Salud. (2000). Plan Nacional de Salud Mental y Psiquiatría. Santiago: Autor.

Ministerio de Salud. (2009). Guía clínica para el tratamiento de personas desde primer episodio esquizofrenia. Santiago: Autor.

Myers, N. L. (2010). Culture, stress and recovery from schizophrenia: Lessons from the field for global mental health. Culture, Medicine, and Psychiatry, 34(3), 500-528. doi:10.1007/s11013010-9186-7

Palma, C. (2007). Intervención psicoterapéutica en la fase inicial de la esquizofrenia: diseño y desarrollo del programa PIPE (Tesis inédita de doctorado). Universitat Ramon Llull, Barcelona, España.
Ricœur, P. (2001a). El modelo del texto: la acción significativa considerada como un texto. En P. Ricœur, Del texto a la acción, Ensayos de hermenéutica II (pp. 169-195). Buenos Aires: Fondo de Cultura Económica de Argentina. (Trabajo original publicado en 1971).

Ricœur, P. (2001b). La función hermenéutica del distanciamiento. En P. Ricour, Del texto a la acción, Ensayos de hermenéutica II (pp. 95-110). Buenos Aires: Fondo de Cultura Económica de Argentina. (Trabajo original publicado en 1975).

Saavedra, J. (2009). ¿Cómo acercarse a historias traumáticas en contextos de rehabilitación psicosocial? Un estudio de caso de un paciente de esquizofrenia paranoide. Salud Colectiva, 5(2), 225-235.

Sullivan, H. S. (1958). El lenguaje de la esquizofrenia. En J. S. Kasanin (Ed.), Lenguaje y pensamiento en la esquizofrenia (pp. 21-34). Buenos Aires: Hormé.

Vallina, O., Lemos, S. y Fernández, P. (2006). Estado actual de la detección e intervención temprana en psicosis. Apuntes de Psicología, 24(1-3), 185-221.

Weiden, P. J., Buckley, P. F. y Grody, M. (2007). Understanding and treating "first-episode" schizophrenia. Psychiatric Clinics of North America, 30(3), 481-510. doi:10.1016/j.psc.2007.04.010

Williams, C. (2008). Insight, stigma, and post-diagnosis identities in schizophrenia. Psychiatry: Interpersonal and Biological Processes, 71(3), 246-256. doi:10.1521/psyc. 